\title{
Cisplatin-Vinorelbine Regimen
}

National Cancer Institute

\section{Source}

National Cancer Institute. Cisplatin-Vinorelbine Regimen. NCI Thesaurus. Code C63407.

A regimen consisting of cisplatin and vinorelbine used to treat advanced-stage non-small lung cancer. 